\title{
A concepção de infância na literatura infantil
}

Maria Cristina Rosa Wenzel

Mestra em Educação pela Faculdade de Educação da Unicamp e professora da

Escola Superior de Administração, Marketing e Comunicação de Sorocaba.

E-mail: criswenzel@aol.com

Sueli Soares dos Santos Batista

Doutora em Psicologia escolar no Instituto de Psicologia da USP.

E-mail: suelissbatista@uol.com.br

Antes tratadas com indiferença ou com cuidados excessivos, a partir do advento da burguesia mercantil, as crianças passaram a ser objeto de discursos que tentam convencer os pais e a sociedade a buscar um comportamento mais racional no trato com elas.

Segundo Ghiraldelli Jr. ${ }^{1}$, o filósofo francês Michel de Montaigne (15331592) foi um dos inauguradores de uma concepção de infância que visava a criticar a indiferença ou paparicação em relação às crianças até então. Do século XVI ao XVIII, tivemos os momentos que estão na base da construção da idéia de infância como uma época fundamental do ser humano. Preservá-la, fazê-la acontecer, evitar interferências desastrosas passaram a ser os objetivos de uma escola reorganizada para ser o mundo da criança. A sociedade era, então, educada pela legislação liberal, marcada pelas cartas de direitos humanos, entre elas, a dos Direitos das Crianças.

Emílio ou da educação foi publicado em 1762, um mês após Contrato social, e como o título já afirma, é um tratado de educação, sem contudo ser propriamente um tratado de pedagogia. No Prefácio, Rousseau ${ }^{2}$ deixa claro que entende por educação a formação do homem, tarefa que considera esquecida e urgente. Ele parece acreditar que está inaugurando um campo do conhecimento pouco explorado: o saber sobre a infância. Embora cite inúmeras vezes os trabalhos de Locke, Montaigne e Buffon, Rousseau crê estar dando início a um novo ramo do conhecimento.

Com o advento da Revolução Industrial, entretanto, as crianças foram

. GHIRALDELLI JR., Paulo. $O$ que é pedagogia. São Paulo: Brasiliense, 1987. p. 13

2. ROUSSEAU, J. J. Emílio ou da educação. Rio de Janeiro: Bertrand Brasil, 1995. p. 5 e ss.

3. GHIRALDELLI JR., Paulo, op. cit., p. 17. crescentemente colocadas no mundo do trabalho. A pedagogia foi convocada a harmonizar esses mundos: o da escola - em que a ênfase estava nos bens culturais e sua fruição - e o do trabalho. Assim é que quase todas as tendências do pensamento pedagógico laico do início do século XX advogam algum tipo de união entre ensino e trabalho. São exemplos as reflexões de Durkheim, Dewey e Gramsci ${ }^{3}$.

O discurso científico sobre a infância articulou-se ainda mais no século XIX, e passou a ser objeto de pesquisa da psicologia, da sociologia, da medicina em 
geral e da puericultura em particular. Para a criança, ser em formação, passou a existir um discurso científico e um mercado específico a fim de ajudá-la a crescer, a ser alguém.

Essa ênfase na infância foi gradualmente tomando o espaço e o tempo de ser criança. Tanto que já não se pode falar de criança como ser genérico, essencial, desvinculado das relações de produção e dos saberes inerentes a essas relações. Quem deu o xeque-mate à noção moderna de infância foi justamente a exaltação que se fez dela, cercando-a de um arsenal que, tendo em vista a aproximação da criança, afastou-se dela a tal ponto que, atualmente, é possível falar que vivemos na Era da Adolescência. Verifica-se uma ampliação do tempo adolescente, fato analisado por Philippe Ariès, que chamou o século XX de século da adolescência. Nele, a adolescência passou a ser a idade favorita. As crianças eram estimuladas a deixar logo o mundo infantil assumindo para si as preocupações do mercado. Vivemos, então, desde o século XX, uma infância sem infância no sentido tradicional.

O mundo social, no qual o indivíduo se insere, apresenta-lhe, a fim de se perpetuar, sonhos, valores, normas, regras, leis, limites de toda ordem que são internalizados; grilhões que o homem assume conscientemente, já que são legados do viver em sociedade, ou inconscientemente, pelo processo de inculcação, de coerção. Em suas etapas de desenvolvimento, não existe uma redoma que isole o indivíduo dos valores, das engrenagens sociais. O imaginário infantil sofre as interferências dos valores e representações histórico-sociais, da moral coletiva de sua época, ou seja, o que a criança fantasia não é desvinculado do real, pois fantasia e real existem num processo de interdependência. Portanto, não existe um mundo à parte da criança, sendo que a produção de objetos culturais única e exclusivamente voltados para as crianças busca muito mais atender aos interesses do mercado que propriamente satisfazer as necessidades infantis genuinas.

Foi a partir do século XIX que escritores e ilustradores se dirigiram cada vez mais à criança por intermédio da mediação ilegítima das suas próprias preocupações, das modas predominantes e dos discursos pedagógicos. Benjamin analisa o percurso histórico da literatura infantil e conclui que nada é mais improfícuo que a tentativa febril de produzir objetos - material ilustrativo, brinquedos ou livros - supostamente apropriados às crianças. Para ele, todo esse arsenal pedagógico, bastante útil para o mercado editorial e a indústria do brinquedo, pode colocar-se como um obstáculo entre a criança e o mundo a ser explorado, experimentado, justamente por dificultar a capacidade imaginativa. A criança não precisa mais imaginar. Os brinquedos brincam por ela; os livros, adaptados ao que seria sua percepção, percebem por ela. Ao privilegiar a moral da história dos contos e fábulas, deixamos de considerar que "as crianças se divertem muito mais com os animais que falam e agem como os homens que com os textos mais ricos de idéias" ${ }^{4}$.

Mas não se trata apenas da ausência da criança na produção feita especialmente para ela. É necessário denunciar como já não se pode mais falar de imaginação sem considerar como as condições objetivas produzem condições
4. BENJAMIN, Walter. Livros infantis antigos e esquecidos. Magia e técnica, arte e política. São Paulo: Brasiliense, 1985. p. 238. (Obras escolhidas, vol. I.). 
subjetivas e uma percepção historicamente diferenciada. Benjamin suspeita da produção cultural para a criança, em particular dos livros infantis, por trabalhar com uma noção idealizada de infância, quer por sua formulação cientificista, quer por sua visão aistórica.

Vale a pena citar a preocupação de Drummond sobre o tema:

O gênero literário infantil tem, a meu ver, existência duvidosa. Haverá música infantil? Pintura infantil? A partir de que ponto uma obra literária deixa de se constituir em alimento para o espírito da criança ou jovem e se dirige ao espírito adulto? Qual o bom livro de viagens ou aventuras destinado a adultos, em linguagem simples e isento de matéria de escândalo, que não agrade à criança? Observados alguns cuidados de linguagem e decência, a destinação preconceituosa se desfaz. Será a criança um ser à parte, estranho ao homem, e reclamando uma literatura também à parte, ou será a literatura infantil algo de mutilado, de reduzido e desvitalizado, porque coisa primária, fabricada na persuasão de que a imitação da infância é a própria infância? Vêm-me à lembrança as misturas de árvores com que se diverte o sadismo botânico dos japoneses: não são organismos naturais e plenos, são anões vegetais ${ }^{5}$.

A literatura infantil não estaria de tal forma desinfetada, segura, mas perfeitamente insípida e desprovida de interesse? Perroti analisa como o adulto julga o que deve ou não ser lido pelas crianças:

É comum ouvirmos, por exemplo, coisas do tipo: a criança sente-se feliz, ameaçada ou angustiada ao ler obras deste ou daquele gênero; a criança necessita deste conteúdo; a criança deve ver isto ou aquilo, pois... E lá vem justificativas ${ }^{6}$.

Segundo ele, as justificativas, em geral, revelam muito mais nossos preconceitos, como também percebeu Drummond, que possíveis necessidades das crianças. Mas o que são essas necessidades senão as forjadas pela indústria cultural? Ao defendermos os interesses de consumo das crianças não estamos sendo cúmplices dos privilégios que a sociedade reservou aos adultos? Privilégios de toda ordem: classistas, sexistas, etários, intelectuais. $\mathrm{O}$ oprimido não tem consciência dessa opressão, submete-se a ela, pois é considerada natural. Processo de naturalização forjado pela indústria cultural, por meio do aparato da produção para crianças e jovens, onde se produzem e padronizam-se os gostos e os desejos através de linguagens e conteúdos banalizados, imbecilizados.

Abramovich, em sua crítica à produção cultural para crianças, confessou

ANDRADE, Carlos. Drummond. Confissões de Minas. Rio de Janeiro: América Editora, 1944. p. 220

6. HELD, J.; PERROTI, E. $O$ imaginário no poder: as crianças e a literatura fantástica. São Paulo: Summus, 1980. p. 9

7. ABRAMOVICH, Fanny. $O$ estranho mundo que se mostra às crianças. São Paulo: Summus, 1983. p. 60. estar cansada das saudades do campo, da beleza das borboletas e do desabrochar $d a$ primavera presentes nos livros infantis, temas esses distantes da realidade atual. Também mostrou irritar-se com aqueles personagens infantis que são "pequenos anões a dizer adultezas, a discursar sobre o que nunca vivenciaram... absolutamente irritantes pelo nada que têm de infantis..."7. Podemos dizer que esses personagens da literatura infantil, abomináveis para Abramovich, não revelam apenas uma falha do escritor. Comprovam também uma face da nossa realidade: o que as crianças querem é não ser crianças, os pequenos anões a dizer adultezas não estão só nos livros infantis. Estão em toda parte: nos programas de TV como Gente inocente, nas escolas, nas ruas, nos lares... A adolescência como padrão 
cultural para todas as faixas etárias não representa uma maturidade precoce para as crianças como se costuma pensar. A adultização delas não significa que disponham atualmente de mais recursos para se colocar no mundo e maiores condições de lidar com os problemas da vida adulta. E muitas delas, crescendo tão rápido, o que podem esperar? As denúncias constantes de pedofilia e violência doméstica, a precocidade no uso e abuso de drogas lícitas e ilícitas, a ansiedade dos pais em preparar os filhos cada vez mais cedo para o mercado de trabalho, a gravidez na pré-adolescência, o brincar administrado em todos os setores da vida social mostram o quanto nossas crianças são infelizes.

Mas essas considerações desgostosas que fizemos são realmente desagradáveis demais para que possam comparecer de maneira crítica no que é produzido para as crianças como resultado de suas necessidades. $\mathrm{O}$ rótulo de infantil, infanto-juvenil, juvenil deve ser analisado com cuidado. Souza, pesquisando sobre literatura juvenil, constatou que os livros assim catalogados pelas editoras não são aqueles em que menores de rua são personagens principais ou tenham algum destaque. Ou seja, são livros feitos sob medida para jovens de classe média, escolares, mais estruturados econômica e socialmente. Mas esses livros, segundo a autora, apresentam personagens conformistas e uma visão igualmente conformista do mundo: "Conformam-se aos limites do que se considera adequado para se expor em livros para jovens escolares, candidatos a vencedores"

Há um outro dado importante ressaltado por essa pesquisadora que, obviamente, também vale para a literatura infantil. Ela analisa o fato de que a literatura juvenil se dirige ao jovem escolar e ao seu professor, procurando ocupar um lugar vazio: o espaço da leitura ausente tanto na experiência do aluno quanto do professor. Portanto, a leitura dos livros sob medida tanto para crianças quanto para jovens adequa-se à falta da experiência da leitura. A ausência de imaginação criticada por Abramovich ${ }^{9}$ na literatura infantil é sintomática da ausência de uma experiência viva, aquela tão esquecida e já substituída pela experiência virtual, digital, televisiva, entre outros simulacros de experiência.

\section{TEXTOS LITERÁRIOS NO PROCESSO ENSINO-APRENDIZAGEM}

A literatura didática e a literatura moralizadora manifestam certa desconfiança para com a ficção. Por que os adultos impõem à ficção transmitir um ensinamento? A ficção responde a uma necessidade de não se contentar com sua própria vida; assemelha-se a um brinquedo. Ela não deveria abrir todas as espécies de portas, permitir ao indivíduo imaginar outras possibilidades de ser, para que, finalmente, possa escolher-se?

É necessário que abandonemos o conceito estereotipado de criança, para que sejam analisados os efeitos da produção cultural a ela dirigida. Podemos pensar as obras literárias em relação à produção cultural individual, imaginação individual nutrida pelo imaginário coletivo, bem como pela produção de leitura, de interpretação por meio da imaginação individual que também é nutrida pelo imaginário coletivo.

8. SOUZA, Malu Zoega de. Literatura juvenil em questão: aventura e desventura de heróis menores. São Paulo: Cortez, 2001. p. 177.

9. ABRAMOVICH, Fanny, op. cit., p. 60. 
Confirmamos esse pensamento com G. Durand, que entende que:

[...] a função da imaginação nas histórias e nas vidas humanas é motivada não pelas coisas em si, mas pela maneira de carregá-las de sentido, segundo o qual ela seria a coisa do mundo mais universalmente partilhada. Por isso, a função fantástica acompanha os empreendimentos mais concretos, modulando a ação estética e social. O imaginário não é, portanto, mera fantasia de romântico, um mundo que paira acima do mundo. Ele é a própria experiência de vida ${ }^{10}$.

A leitura do real funde-se com o imaginário. Poesia, contos, desenho, música, expressão corporal: descoberta dos diversos caminhos do imaginário na pessoa. Há romances que desbloqueiam a imaginação, que fazem explodir as estruturas fixas, estereotipadas, que transformam o universo cotidiano.

Dar à literatura papel pedagógico elementar, em vez de fazer dela essa grande educadora indireta, é perigoso para a produção e leitura de textos literários. A produção cultural para crianças e jovens sempre esteve ligada à formação escolar. Pedagogizar a leitura resulta nessa padronização que ora denunciamos. Os textos literários que não são feitos sob medida para o público escolar trazem a possibilidade de um maior respeito ao tema tratado e ao leitor.

10. DURAND, G. Mito e sociedade: a mitanálise e a sociologia das profundezas. Lisboa: Regras do Jogo, 1983. p. 54.

11. DINORAH, Maria. O livro infantil e a formação do leitor. Petrópolis: Vozes, 1996. p. 33.

12. Ibid., p. 34.

13. LOBATO, Monteiro. A menina do narizinho arrebitado. São Paulo: Revista do Brasil, 1920 p. 5 e ss.

14. CAPPARELLI, Sérgio. TV e criança: a emergência do mercado de bens culturais. In: Pacheco, Elza Dias (Org.). Televisão, criança, imaginário e educação. São Paulo: Papirus, 1998. p. 158.

\section{A LITERATURA INFANTIL NO BRASIL}

A literatura infantil no Brasil surgiu no século XIX, como literatura oral, misturando misticismo, miticismo e folclore, que se somavam, segundo Dinorah ${ }^{11}$, a elementos indígenas. São marcantes, nessa época, as contadoras de histórias.

Utilizando o breve histórico feito por ela, afirmamos que Carlos Jansen e Alberto Figueiredo Pimentel ${ }^{12}$ foram os primeiros brasileiros a se preocupar com a literatura infantil no país, traduzindo as mais significativas páginas dos hoje considerados clássicos por crianças e adultos. Com Thales de Andrade, em 1917, é que a literatura infantil nacional teve início. Foi em 1921 que Monteiro Lobato estreou - com A menina do narizinho arrebitado ${ }^{13}$, apresentando ao mundo Emília - a mais moderna fada humanizada. A partir de então, o mercado editorial cresceu muito, e assistiu-se ao que se convencionou chamar de boom da literatura infantil.

Entre nós, os primeiros livros foram concebidos com objetivos estritamente pedagógicos. Histórias ou poemas infantis destinavam-se a formar na criança hábitos de higiene ou de patriotismo. Uma exceção foi Monteiro Lobato, que trouxe uma prosa vigorosa e criou personagens, especialmente femininos, com uma visão mais crítica da realidade.

Na primeira metade do século XX, iniciou-se a exploração de mais um produto destinado ao segmento infantil: as histórias em quadrinhos, fruto da internacionalização da indústria de comics norte-americanos. Essa produção intensificou-se, principalmente a partir dos anos de 1960, com os contratos entre a Editora Abril e os estúdios de Walt Disney. As crianças brasileiras passaram, então, a receber sistematicamente as histórias de Mickey Mouse, Tio Patinhas e Pato Donald ${ }^{14}$.

Vários artistas brasileiros aventuraram-se na arte dos quadrinhos, mas a indústria editorial do país fechava-se para a idéia de publicar trabalhos que não 
fossem reproduções dos produtos importados da indústria norte-americana: as mesmas características das personagens, contextos assemelhados e exploração de temas desvinculados de nossa realidade. Essa imposição das distribuidoras fez com que muitos artistas brasileiros ficassem desestimulados e abandonassem seus projetos. Poucos conseguiram firmar-se nessa arte. Dentre eles, destaca-se Maurício de Sousa, que compreendendo o preconceito das editoras em relação ao produto nacional, na procura por um espaço para divulgar sua arte, acabou incorporando as exigências de mercado.

Os desenhos de Maurício de Sousa, segundo Cirne ${ }^{15}$, não têm a mesma brasilidade de Pererê, de Ziraldo. Seus desenhos têm elementos mais universais do que brasileiros - ou mais universais do que latino-americanos. Características que, como já dissemos, são conseqüências das exigências impostas aos produtores de quadrinhos brasileiros, conseqüência que se reflete, também, no cinema de animação. Se, de um lado, o material norte-americano foi importante na formulação de parâmetros estéticos, por outro, não havendo uma seleção prévia do que importávamos, foi prejudicial uma vez que condicionou ideologicamente gerações inteiras no bombardeio massificante de mensagens alheias à transformação do nosso contexto social.

Nos anos de 1980 e 1990, houve uma expansão considerável do mercado de bens culturais para crianças que se percebe nos sentidos vertical e horizontal. Segundo Capparelli ${ }^{16}$, a expansão vertical define-se como a incorporação de homens e mulheres desde seu nascimento até a morte dentro da lógica de consumo (do recém-nascido ao moribundo temos diversas fatias do mercado). A expansão horizontal é o aumento gradativo da gama de produtos oferecidos a essas fatias. Um exemplo disso é a forma como são lançados brinquedos vinculados a desenhos animados de programas de TV, cuja apresentadora lança um disco e uma série de produtos nada diversificados na sua temática. Do álbum de figurinhas ao filme, o círculo se fecha.

No capitalismo periférico, a literatura sofre um problema básico: as sociedades dominadas pelo analfabetismo e pela indústria cultural não oferecem muitas perspectivas para a literatura. O que temos, na verdade, é um leque de adaptações dos clássicos que assim reduzidos são esvaziados da sua instância crítica. Walt Disney, nesse sentido, é a indústria que, apropriando-se dos contos de fadas, adocicou-os de tal forma a retirar deles os conflitos que lhes são essenciais ${ }^{17}$. Mas não só Walt Disney. A produção nacional dá poucos sinais de se opor ao status quo: por vezes dirige-se a uma criança que não existe há bastante tempo.

Quanto à leitura, infelizmente, muitos dos livros que se incluem nos títulos da chamada literatura infantil são protótipos dos produtos forjados na indústria cultural: reproduzem a linguagem dos programas veiculados pela televisão - a linguagem coloquial banalizada -, os temas populares que possam dar ibope - elementos da narrativa criados em série (como numa linha de produção), mas que atingem o público infanto-juvenil por carregar os valores incutidos ideologicamente pela sociedade de consumo, reproduzindo e mantendo a ordem social vigente.
15. CIRNE, M. A linguagem dos quadrinhos: o universo estrutural de Ziraldo e Maurício de Sousa. Petrópolis: Vozes, 1971. p. 61-69.

16. CAPPARELLI, Sérgio, op. cit., p. 157-158.

17. ABRAMOVICH, Fanny. Literatura infantil: gostosuras e bobices. 5. ed. São Paulo: Scipione, 1999. p. 121. 


\section{RUBEM ALVES E MARIA DINORAH: DETENDO-SE NO PARTICULAR}

Nos limites deste trabalho, elegemos como objeto de reflexão a produção literária de Rubem Alves e de Maria Dinorah. Inicialmente, queremos indicar que essa escolha se definiu prioritariamente pelos critérios descritos a seguir.

Rubem Alves não pode ser classificado como escritor de literatura infantil, mas seus livros têm sido adotados por professores do ensino fundamental e até indicados por psicólogos infantis para que temas complicados possam ser trabalhados com as crianças. Maria Dinorah foi convidada pela Secretaria de Cultura de São Paulo a excursionar por escolas brasileiras para ler e discutir seus livros com as crianças. O que está ausente em Rubem Alves - a discussão sobre o poder e a sociedade - fervilha na poesia de Maria Dinorah. Podemos dizer que os autores em questão são díspares, falando de e para diferentes realidades, diferentes crianças, diferentes concepções de infância.

\section{Rubem Alves}

Entre as obras de Rubem Alves, selecionamos alguns títulos da Coleção "Estórias para pequenos e grandes": Os morangos, A operação de Lili, A selva e o mar, A planície e o abismo e A montanha encantada dos gansos selvagens.

O nome da coleção, até o momento composta de 12 livros $^{18}$, é sintomático de uma visão do indivíduo não fracionado em faixas etárias. Rubem Alves, ao abordar problemas de difícil tratamento, reconhece o quanto é complicado falar de maneira simplificada sobre assuntos como, por exemplo, a doença, a morte, a separação. Portanto, o autor respeita o leitor, seja ele criança ou adulto, ao tentar falar para ambos, sem fazer concessões na linguagem. Não deixa de respeitar o tema não o adequando a uma compreensão infantil preestabelecida. Em relação ao tema da separação de pais, o autor, ao colocar as idéias no papel, percebeu que não eram adequadas para crianças e não conseguiu falar disso de uma forma infantil. Ele mesmo considera o livro A selva e o mar um texto difícil. Acreditamos ser isso uma virtude, já que falar de temas complexos de maneira simples é tentar simplificá-los. O esforço de simplificação em nome da comunicabilidade fácil, na maioria das vezes, resulta em uma não-comunicação. Há assuntos não-comunicáveis, indizíveis mesmo, e simplificar seu tratamento é banalizá-los.

Rubem Alves procura desmistificar a visão de uma infância feliz, simples-

18. A Coleção "Estórias para pequenos e grandes" encontra-se em andamento e conta com 13 títulos no momento. (N.E.)

19. ALVES, Rubem. São Paulo: Paulus, 1985. p. 5. (Coleção Estórias para pequenos e grandes). mente lúdica e imaginativa, em que temas tristes são proibidos. Assim é que na introdução de todos os números da coleção, numa espécie de esclarecimento, ele alerta: "O mundo das crianças não é tão risonho quanto se pensa. Há medos confusos, difusos, as experiências das perdas, bichos, coisas, pessoas que vão e não voltam..."19.

Então, a idéia de uma infância gostosa, distante dos conflitos e temas dolorosos, é francamente criticada pelo autor. Assumir o temor, ter tanto medo 
quanto a realidade merece, parece ser a postura do autor diante dessa infância nem sempre feliz.

As histórias de Rubem Alves, que ora analisamos, são escritas para ser contadas por alguém. Esse alguém é o único capaz de, auxiliado pelo livro, aplacar o medo dizendo: Estou aqui, meu filho... Nesse ponto, temos elementos interessantes: a valorização do livro como lugar do saber e da experiência e o momento da leitura carinhosa que rompe barreiras familiares. Mas, também, o espaço da experiência familiar, da cumplicidade, ocupado agora pela leitura, por um tratamento extrínseco do nosso cotidiano, por um dado facilitador de nossos conflitos: o livro ocupando o espaço de um silêncio que se fez entre quatro paredes.

Se o medo não pode ser aplacado pelo objeto livro, pode sê-lo por quem o utiliza: o contador/leitor das histórias, mediador entre o autor e o leitor final. Os livros da Coleção "Estórias para pequenos e grandes" foram concebidos para viabilizar um encontro, sobretudo familiar, mostrando o quanto esse momento não é algo espontâneo, natural.

Questionamos a função última desses livros: falar de um medo que pode ser aplacado. Sua finalidade é consoladora, harmonizadora. Abramovich diz-nos que o tema da morte é, assim como no cotidiano, mal resolvido na literatura infantil: o tema é ainda pouco explorado, como se a criança não se defrontasse com ela. Não há a morte, mas múltiplas possibilidades de morte, assim como há múltiplas espécies de vida. A morte não pode ser apenas compreendida como o fechamento natural de um ciclo, embora ela também possa ser isso. A morte também é:

[...] provocada de modo irresponsável, leviano, segundo a lei do mais forte, profundamente injusta, de civilizações, de culturas, de crenças, de bichos, plantas, pessoas... De tudo e todos que fazem parte do mundo e que deixam de fazer por razões não-humanas, não-solidárias, nem progressistas ${ }^{20}$.

Ou seja, a morte não pode ser vista apenas sob a ótica de um processo natural. Diariamente, todos nós temos contato com formas violentas de viver e, portanto, de morrer. Dar a essa temática um verniz naturalizador como um simples fechamento de um ciclo é contribuir para sua banalização. Algo como a história de A montanha encantada dos gansos selvagens, em que "o velho ganso nem precisou bater as asas, ele estava leve, leve... e ele partiu..." ${ }^{21}$. Se está correto afirmar que o trágico não vem a conta-gotas, tratá-lo como se assim o fosse é abdicar de falar dele honestamente com a criança.

Portanto, encontramos, de forma geral, nos textos que ora analisamos, a busca de suavizar os conflitos que vivemos: a tentativa de tornar a realidade mais digerível. Isso fica claro, por exemplo, em Os morangos. O homem dependurado sobre o abismo, esquecido de tudo o mais, comeu um dos morangos: "Estava delicioso!... Sorriu, então, de que na vida houvesse coisas tão belas"22. No entanto, ressaltamos, continuou dependurado sobre o abismo, apesar de ter à sua frente algum remédio que dê alegria.

Podemos argumentar superficialmente que o contexto social desses abismos, planícies, montanhas encantadas, selvas e mares é completamente silenciado.
20. ABRAMOVICH, Fanny, op. cit., p. 114.

21. ALVES, Rubem. A montanha encantada dos gansos selvagens. 9. ed. São Paulo: Paulus, 1987. p. 6. (Coleção Estórias para pequenos e grandes).

22. Id. Os morangos. 5. ed. São Paulo: Paulus, 1987. p. 14. (Coleção Estórias para pequenos e grandes). 
A paisagem natural em que os enredos se desenrolam mascara a segunda natureza das coações sociais e psíquicas que a humanidade tem-se imposto ao longo da história. Em profundidade, avaliamos que o aspecto social é tratado na forma mesmo em que as histórias são concebidas: não há lugar para a indignação no enfrentamento da dor, seja individual, seja coletiva. Seu objetivo é fazer com que o sentimento de abandono, de medo, de perda seja substituído pelo sentir-se em casa (A selva e o mar) onde quer que estejamos, quando muitos nem sequer têm pais para poder dividir-se entre eles, nem sequer têm casa, nem sequer têm lar. Sem falar que há aqueles que são estrangeiros na própria casa.

O leitor de Rubem Alves é convidado, então, a aprender a enfrentar as durezas dos abismos da vida como quem enfrenta as agruras de uma paisagem natural. São as histórias individual e coletiva interpretadas como história natural, petrificada. Entre a planície e a montanha encantada há um caminho previamente traçado. Não é a montanha que é encantada, mas o indivíduo que tem de descobrir e seguir essa trajetória... sozinho. Alves fala ao seu leitor do desamparo do indivíduo, o que é belo, o que é um dever. Mas deixa-o por sua conta e sorte, relegando-o à auto-ajuda. São histórias para pequenos e grandes resignados.

\section{Maria Dinorah}

Maria Dinorah, gaúcha, é jornalista, escritora e mestra em Educação. Dedica-se especialmente ao público infanto-juvenil e costuma autoproclamar-se andarilha da palavra. Sua atitude é a do iluminista: nasce da experiência, especialização e mobilização contínua, conforme palavras da própria Dinorah, na introdução da obra $O$ livro infantil e a formação do leitor. Esse livro documenta sua visitação às escolas como parte de um projeto da Secretaria de Cultura de São Paulo. A autora, poetizando, fala para e de uma criança que ela concebe como especificamente brasileira, vivendo problemas inerentes à nossa realidade. Daí o seu tom engajado, denunciador.

Ao fazer suas poesias e ao falar sobre elas, o tom de Dinorah é o de quem proclama problemas urgentes: "Sabemos que há muito, mas muito mesmo, por fazer, neste país de poucas letras e excessiva omissão" ${ }^{23}$. Nesse sentido, entendemos que ela não procura tratar de temas universais de maneira universalizante. Seu repertório é o cotidiano, quase sempre pobre, das crianças brasileiras. Transitam nos seus versos meninos que roubam pão, o bebê Pelé, as panelas das favelas que fazem greve de fome, Maria chocolate carapinha do Brasil, o menino nordestino, tadinho tiritando de frio, o aluno da favela... Sua poesia é sua arma, seu compromisso de vida.

Ao contrário de Rubem Alves, sua inquietação não são questões existenciais.

23. DINORAH, Maria. O livro infantil e a formação do leitor. Petrópolis: Vozes, 1995. p. 9
Seu tema é a luta, nem sempre bem-sucedida, pela sobrevivência. Está preocupada com a pobreza material e a intelectual da maioria de nossas crianças. $\mathrm{O}$ universo em que trabalha não é aquele idealizado por Rubem Alves, o ambiente acolhedor de um pai que lê para o filho antes do adormecer. Dinorah não es- 
pera a cumplicidade dos pais que, no seu dizer, "premidos por uma sociedade injusta, a exigir-lhes os maiores sacrifícios para sobreviverem, não dispõem de tempo nem estão preparados para fazer leitores os seus filhos"24.

Dinorah fala da nossa dívida social esperando a cumplicidade da criança, como observamos no belo poema Quando eles souberem ${ }^{25}$ :

Os meninos que brincam,

Talvez não saibam não,

Que há meninos na luta

Por um pouco de pão.

Os meninos que estudam,

O fazem sem notar

Que há meninos sonhando

Como poder estudar.

Há meninos com tudo,

A viver muito bem,

Que talvez não entendam

Por que tantos não têm.

E há meninos vivendo

O momento da paz,

Sem sequer perceberem

Do que a guerra é capaz.

Mas quando eles souberem,

Tudo isso vai passar,

Pois está nas crianças

$\mathrm{O}$ poder de mudar.

A autora pressupõe, portanto, que as crianças leitoras de seus textos sejam aquelas que pelo acesso que tiveram a eles, estejam em melhores condições para compreender, indignar-se e serem agentes de transformação.

\section{ADEUS, MENINOS!}

Dinorah deseja não necessariamente preservar o mundo da criança. Assim como Rubem Alves, reconhece que este mundo não é sempre tão feliz e tão específico quanto imaginamos. Fala da angústia, do medo, mas não procura apaziguá-lo. Seu interlocutor é a criança não como indivíduo em busca de seu caminho de Santiago. Chama a criança para olhar em volta de si, convocando-a para a ação, não para a contemplação. Sua apreensão exige menos auto-reflexão que crítica social. 
Com isso, não queremos dizer que Dinorah fala da realidade e Rubem Alves, não. A realidade sobre a qual se debruça Alves é intimista, é a da privacidade, do indivíduo burguês que busca a autonomia, o autoconhecimento, o si mesmo, a consciência moral, como diria Rousseau. Assim como esse indivíduo, a capacidade de construir, experienciar e transformar o mundo está em franco desaparecimento.

Dinorah tem o olhar atento no coletivo, numa realidade configurada e entendida no social. Ela tem pressa, como Descartes, de que essa criança saia de sua menoridade intelectual, que trabalhe por sua emancipação e a dos demais, o que também a aproxima de Kant.

Consideradas as diferenças, tanto Rubem Alves como Maria Dinorah, com suas produções, procuram ir ao encontro de uma infância que não deve ser entendida como conceito invariante, idealizado, como a eterna criança que dormita em cada um, mas de uma infância que nos tem assustado por ser nada infantil. A infantilização fica por conta da produção cultural estereotipada. Quanto às crianças de carne e osso, essas tentam resistir.

Resumo: A construção da idéia de infância que, a partir do século XVI, conheceu uma importante mudança, ou seja, a consideração pelo adulto da especificidade da criança, acabou por aprisioná-la nessa fase de desenvolvimento. A partir do século XIX, a cumplicidade entre o artesão anônimo e a criança desapareceu: escritores e ilustradores dirigiram-se cada vez mais à criança por meio da mediação ilegítima das suas próprias preocupações, das modas predominantes e dos discursos pedagógicos. Todo esse arsenal pedagógico, bastante útil para o mercado editorial e a indústria cultural do brinquedo, pode colocar-se como obstáculo entre a criança e o mundo a ser explorado, experimentado, justamente por dificultar a capacidade imaginativa. Este artigo propõe algumas perguntas que só poderão ser respondidas empiricamente, por meio da análise de livros produzidos para o público infantil.

Palavras-chave: indústria cultural, literatura infantil, infância, modernidade.
Abstract: The concept of childhood has evolved through time and undergone main changes all along XVI century. During this period adults have figured out particular aspects that make a child unique in contrast to adults and this ended up in an imprisonment of children in this developmental period. From XIX century on, complicity between anonymous artisans and children disappears: writers and painters increasingly addressed children through illegitimate mediation of their own worries, prevailing fads and pedagogical discourses. All this pedagogical army, very useful to editorial market and toy industry, may be an obstacle between children and the real world to be explored and experienced, since it creates difficulties to development of children's imaginative skills. This question can only be answered through analysis of children's literature.

Keywords: culture industry, children's literature, infancy, modernity. 